\title{
Elevated levels of circulating biomarkers of cell death (nucleosomes) in the patients with plaque psoriasis treated with the Goeckerman regimen
}

\author{
Ranna $\mathrm{D}^{1}$, Andrys $\mathrm{C}^{2}$, Krejsek $\mathrm{J}^{2}$, Hamakova $\mathrm{K}^{4}$, Kremlacek $\mathrm{J}^{3}$, Fiala $\mathrm{Z}^{1}$, Borsky $\mathrm{P}^{3}$, Borska $\mathrm{L}^{3}$ \\ Institute of Hygiene and Preventive Medicine, University Hospital, Hradec Kralove, Czech Republic. \\ borka@Ifhk.cuni.cz
}

\begin{abstract}
Background: Nucleosomes are complexes that are formed during apoptosis. Psoriasis is a chronic skin disease characterized by keratinocyte hyperproliferation and anti-apoptotic features. Presented study was focused to expression of circulating biomarkers of cell death (circulating nucleosomes, CN) during Goeckerman therapy of psoriasis (UV, PAHs).

Methods: In a group of patients with psoriasis (19), treated with Goeckerman regimen (GR), we evaluated their level of $\mathrm{CN}$, level of chromosomal aberration in peripheral lymphocytes (CA), level of urinary 1-hydroxypyrene (1-OHP) and their value of Psoriasis Area and Severity Index (PASI).

Results: Following the treatment, the serum level of $\mathrm{CN}$ and urinary level of $1-\mathrm{OHP}(p<0.05)$ were significantly increased $(p<0.01)$. We found significant correlation between $C N$ and urinary level of 1-OHP after GR $(r=0.57$; $p<0.05)$. Immediately after the treatment we found significantly increased total numbers of abnormal chromosomes $(A B B ; p<0.01)$ and structurally abnormal chromosomes (SAB; $p<0.05)$.

Conclusions: We found slightly (but statistically significant) elevated level of circulating biomarkers of cell death (nucleosomes) in patients with plaque psoriasis treated with GR (PAHs, UV radiation). We suppose that elevated level of $\mathrm{CN}$ is a result of combination of the positive effects of GR and its weak genotoxic effect (mainly PAHs). Conclusions are supported by significant correlation between $\mathrm{CN}$ and urinary level of 1-OHP after GR and significantly elevated level of CA after GR (Tab. 2, Fig. 1, Ref. 28). Text in PDF www.elis.sk.

Key words: psoriasis, apoptosis, nucleosomes, biomarker.
\end{abstract}

Nucleosomes are complexes (DNA and histones) that are formed during cell death/apoptosis (1). After disintegration of the plasma membrane, they are released from apoptotic cells into the circulation (2). Various benign and malignant pathologic conditions including cancer, sepsis, and graft-vs-host autoimmune diseases as well as after trauma and ischemia or therapeutic causes increase the level of circulating nucleosomes $(\mathrm{CN})(3,4,5)$.

Apoptosis seems to be one of the key mechanisms in the process of carcinogenesis, and may be induced by different environmental mutagens such as polycyclic aromatic hydrocarbons (PAHs) or ultraviolet radiation (UVR) $(6,7,8)$.

\footnotetext{
${ }^{1}$ Institute of Hygiene and Preventive Medicine, University Hospital, Hradec Kralove, ${ }^{2}$ Institute of Clinical Immunology, Alergology, University Hospital, Hradec Kralove, ${ }^{3}$ Institute of Pathological Physiology, Faculty of Medicine, Charles University, Hradec Kralove, Prague, and ${ }^{4}$ Clinic of Dermal and Venereal Diseases, University Hospital, Hradec Kralove, Czech Republic
}

Address for correspondence: L. Borska, MD, PhD, Institute of Pathological Physiology, Charles University in Prague, Faculty of Medicine, Simkova 870, CZ-500 38 Hradec Kralove, Czech Republic. Phone: +420.49.5816478, Fax: +420.49.5513597

Acknowledgements: Supported by Charles University in Prague, Faculty of Medicine in Hradec Králové, Czech Republic, project PRVOUK P37/09 and SVV-2012-264901.
Goeckerman regimen (GR) is still used in dermatological therapy of psoriasis in form of combined application of crude coal tar ointment (CCTs) and exposure to ultraviolet radiation (UVR) (9, $10,11)$. GR is an effective low-cost therapy, however, nowadays the use of GR is reduced due to supposed mutagenicity and carcinogenicity of CCTs $(12,13,14)$. Therapeutic CCTs ointment contains numerous polycyclic aromatic hydrocarbons (PAHs) that are recognized as potential carcinogens requiring bioactivation. When exposure to PAHs occurs together with exposure to UVR, potentiation of mutagenic/carcinogenic effects can be expected $(15,16,17)$.

The main global objective of presented study was to describe changes in expression of $\mathrm{CN}$ after GR. The results were completed by the levels of chromosomal aberration in peripheral lymphocytes (CA, marker of genotoxic effect) and urinary 1-hydroxypyrene (1OHP, marker of exposure to PAHs).

\section{Material and methods}

The monitored group included 19 patients (average age of 39 years, age variance $18-56,11$ smokers and 8 nonsmokers) with chronic stable plaque psoriasis. The patients who had prior exposure to CCTs and /or artificial UVR were excluded from the monitored group. Before the study, all patients were graded according to Psoriasis Area and Severity Index (PASI) (18). The 
Tab. 1. The influence of GR to levels of selected indicators.

\begin{tabular}{lcccc}
\hline time of sample collection & $\mathrm{n}$ & $\begin{array}{c}\text { nucleosomes in serum }(\mathrm{ng} / \mathrm{ml}) \\
\text { median [lower-upper quartile] }\end{array}$ & $\begin{array}{c}\text { 1-OHP/creatinine in urine }(\mu \mathrm{g} / \mathrm{g}) \\
\text { median [lower-upper quartile] }\end{array}$ & $\begin{array}{c}\text { PASI (dimensionless) } \\
\text { median [lower-upper quartile] }\end{array}$ \\
\hline immediately before GR & 19 & $4.3[1.3-7.8]$ & $4.8[0.5-7.6]$ & $6.8[5.5-15.9]$ \\
immediately after GR & 19 & $7.4[3.6-15.6]$ & $\mathrm{p}<0.05$ & $9.0[5.5-12.4]$ \\
significance of differences & & $\mathrm{p}<0.01$ & $\mathrm{p}<0.001$ & $13.2-22.8]$ \\
\hline
\end{tabular}

The nucleosomes, 1-OHP and PASI values are presented as median [lower-upper quartile] because of non-normal distribution of data.

Wilcoxon matched-pairs test was used for statistical evaluation.

Tab. 2. Chromosomal aberration in peripheral lymphocytes (CA).

\begin{tabular}{lccc}
\hline chromosomal abnormalities & $\begin{array}{c}\text { immediately before GR }(\mathrm{n}=19) \\
\text { median [lower-upper quartile] }\end{array}$ & $\begin{array}{c}\text { immediately after GR }(\mathrm{n}=19) \\
\text { median [lower-upper quartile] }\end{array}$ & statistical significance of differences \\
\hline ABB & $0.0(0.0-0.0)$ & $1.0(0.0-1.0)$ & $\mathrm{p}<0.01$ \\
SAB & $0.0(0.0-0.0)$ & $1.0(0.0-1.0)$ & $\mathrm{p}<0.05$ \\
NAB & $0.0(0.0-0.0)$ & $0.0(0.0-0.0)$ & $\mathrm{NS}$ \\
\hline
\end{tabular}

The ABB (SAB, NAB) values are presented as median [lower-upper quartile] because of non-normal data distribution. ABB: total number of aberrant cells; SAB: number of cells with structural aberrations; NAB: number of cells with numerical aberrations. $n=$ number of subjects

Wilcoxon matched-pairs test was used for statistical evaluation.

group was tested immediately before and immediately after therapy discontinuation.

The duration of GR was individualized (average 13 days, range 8-22 days). The CCTs ointment (containing $3 \%$ CCTsPix Lithantracis) was applied daily to affected skin (27-73\% of body surface), and at the same time, the patients were exposed to ultraviolet-A (UVA) and ultraviolet-B (UVB) radiation. UVR administration was individualized according to disease severity in intervals ranging from 1-20 min. The density of UVB (134.45 $1 \mathrm{~W} / \mathrm{cm} 2)$ and UVA $\left(245.60 \mathrm{lW} / \mathrm{cm}^{2}\right)$ was controlled by spectroradiometer Sola-Scope 2000 (Solatell Ltd., UK).

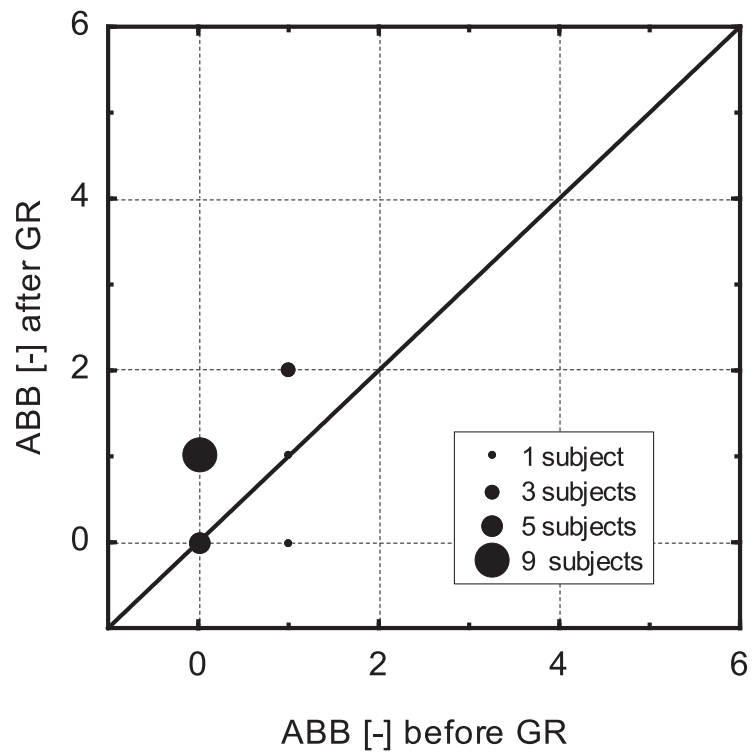

Fig. 1. Total number of aberrant cells (ABB) immediately before and after GR. Notices: Scatter plot comparing the total number of aberrant cells $(\mathrm{ABB})$ immediately before and after GR. Each point represents a single subject $(n=19)$. The subjects located below the diagonal $(n=1)$ had lower ABB after therapy; this difference was statistically significant across the sample (see Tab. 1).
Urine samples were collected immediately before and after GR. Analysis of urinary 1-hydroxypyrene (1-OHP) has been carried out by modified HPLC method (19). Concentration of 1-OHP was adjusted to urinary creatinine.

Heparin-treated peripheral blood samples were collected before and after GR and subsequently the levels of CA and CN were analyzed. CA was carried out by using standardized method (20). The presence of $\mathrm{CA}$ in cells undergoing mitosis was assessed microscopically. The total numbers (ABB) of abnormal chromosomes (structural; SAB and numerical; NAB) were determined in 100 metaphase lymphocytes from each patient. Serum level of CN was evaluated by ELISAs (Roche, Mannheim, Germany).

Data were analyzed by using STATISTICA v. 8 software (Statsoft, Inc., Tulsa, USA). Because the Shapiro-Wilk W-test of normality had rejected the hypothesis of normal distribution, nonparametric tests were used. Data were analyzed by the Wilcoxon matched pairs test. The effect of smoking was evaluated by the Mann-Whitney U test and the association between selected parameters was evaluated by Spearman Rank Order Correlations.

The Ethics Committee of the Medical Faculty of Charles University at University Hospital and Purkyne Military Medical Academy in Hradec Kralove reviewed and approved this study. Patients were selected sequentially from the Department of Dermatology and Venerology, University Hospital in Hradec Kralove, Czech Republic.

\section{Results}

Following the treatment, urinary level of $1-\mathrm{OHP}(\mathrm{p}<0.05)$ and serum level of $\mathrm{CN}$ was significantly increased $(\mathrm{p}<0.01)$ (Tab. 1). Our findings indicated significant correlation between $\mathrm{CN}$ and urinary level of 1 -OHP after GR $(r=0.57 ; \mathrm{p}<0.05)$. In addition, after GR, we found significantly increased total numbers of abnormal chromosomes (ABB; $<<0.01$ ) (Tab. 2, Fig. 1) and structurally abnormal chromosomes ( $\mathrm{SAB} ; \mathrm{p}<0.05)$ but not numerically abnormal chromosomes (NAB; NS) (Tab. 2). We did not find a significant correlation between smoking vs. nonsmoking patients 
and levels of 1-OHP, ABB, CN. High therapeutic efficacy of GR was confirmed by PASI score which has declined significantly after GR ( $\mathrm{p}<0.001)$ (Tab. 1). We did not find correlation between PASI score and 1-OHP, $\mathrm{ABB}$ or $\mathrm{CN}$, respectively.

\section{Discussion}

In response to environmental mutagens, $\mathrm{p} 53$ protein activates genes, the products of which lead to cell cycle arrest, DNA repair and, in case of irreparability, to cell apoptosis (21). Massari et al supposed that the major role in skin cancer development is given by pro-apoptotic p53 molecule or tumor suppressor gene, the mutation of which leads to resistance of DNA-damage cell to apoptosis (22). Apoptosis pathways provide an efficient safeguard mechanism against cancer. They are mediated via cell-intrinsic response and immune mediated extrinsic signal (23). Cell-intrinsic pro-apoptotic pathways are largely controlled primarily by above mentioned p53 proteins, whereas the extrinsic induction of apoptosis is initiated by death ligands such as cytokine soluble FasL (sFasL) $(23,24)$. The results of our previous study indicated that GR may modulate apoptosis through both intrinsic and extrinsic pathways (7). The serum levels of $\mathrm{p} 53$ protein and sFasL were significantly higher after GR ( $<<0.05$ and $\mathrm{p}<0.01$, respectively) (7).

Apoptosis is programmed as a cascade of enzymatic reaction leading to DNA fragmentation and disintegration of cellular structures (1). Immunogenic cell death products such as nucleosomes are released into the circulation from apoptotic cells upon pathologic or therapeutic causes and stimulate the innate and adaptive immune system (2). CN were recognized as a biomarker of cell death, which might be useful for cytotoxic therapeutic monitoring $(3,4)$.

A normal level of $\mathrm{CN}$ in healthy persons moving around 36 $\mathrm{ng} / \mathrm{ml}$ (25). Before the therapy, the level of $\mathrm{CN}$ in patients with colorectal cancer reached $191 \mathrm{ng} / \mathrm{ml}$ (25). After the irradiation, the levels of $\mathrm{CN}$ were found to be significantly increased, namely up to $239 \mathrm{ng} / \mathrm{ml}$ (after 24 hours) and $677 \mathrm{ng} / \mathrm{ml}$ (after 48 hours) (25).

Psoriasis is a chronic skin disease characterized by keratinocyte hyperproliferation and anti-apoptotic features (26).

In agreement with this characteristic, we found low levels of $\mathrm{CN}$ in psoriatic patients before the therapy $(4.3 \mathrm{ng} / \mathrm{ml})$ and this fact indicates depressed activity of apoptotic mechanisms. After treatment, we have seen an increase in the value of $\mathrm{CN}$ $(7.4 \mathrm{ng} / \mathrm{ml})$. The increase was significant $(\mathrm{p}<0.01)$, however, still almost five times lower than the normal level of the CN (25). The increase in the level of $\mathrm{CN}$ can be possibly attributed to the success of therapy (healing and return to normal state). But on the other hand, it is possible to attribute this growth also to genotoxic effects of PAHs and UVR. Both these factors are assumed to be the possible sources of genotoxic hazard, however, the intensity of UVR was generally very low (see methods) and therefore we assume that the exposure to genotoxic PAHs is probably major genotoxic factor. The presented presumption supports the significant correlation between $\mathrm{CN}$ and urinary level of 1-OHP after GR ( $\mathrm{r}=0.57 ; \mathrm{p}<0.05)$. We cannot exclude completely the possibility of moderate mutual potentiation of mutagenic/ /carcinogenic effects of PAHs and UVR. In the case of application of CCTs ointment containing $3 \%$ CCTs-Pix Lithantracis, the overall genotoxic potential of the therapy was evaluated as weak. In short, it is likely that the observed slightly elevated level of $\mathrm{CN}$ is a result of a combination of the positive effects of therapy (see PASI score) and its weak genotoxic effect (mainly PAHs). At present, unfortunately, it is not possible to compare our results with scientific literature, because the studies aimed at analyzing the levels of $\mathrm{CN}$ in patients treated with GR are so far lacking.

Pyrene is a typical polycyclic aromatic hydrocarbon and 1-OHP is its major metabolite. ${ }^{19}$ The significantly increased level of urinary 1-OHP after GR confirmed intensive dermal absorption of pyrene and its penetration into blood circulation $(\mathrm{p}<0.05)$. The ranges of 1-OHP urinary concentrations of $0.5-7.6 \mu \mathrm{g} / \mathrm{g}$ creatinine (before GR) and 5.5-15.9 $\mu \mathrm{g} / \mathrm{g}$ creatinine (after GR) were similar to the ranges which we found in our previous study with a different group of 20 patients, namely $0.45-3.03 \mu \mathrm{g} / \mathrm{g}$ creatinine (before GR) and 0.93-11.3 $\mu \mathrm{g} / \mathrm{g}$ creatinine after GR (7). Due to a relatively high and stable concentration of pyrene in the mixtures of PAHs, this hydrocarbon is generally considered to be a suitable representative of the whole PAHs group. As to the similarity of the structure and physico-chemical properties of PAHs, we can assume that other PAHs (including carcinogenic and mutagenic PAHs) penetrate into the blood circulation with similar intensity.

The elevated level of chromosomal aberration in peripheral lymphocytes indicates an increased risk of genotoxic exposure. Clastogenic activity of PAHs has been demonstrated in human lymphocytes and in several studies in vivo $(20,27)$. After GR, we found significantly increased ABB $(p<0.01)$ and SAB $(p<0.05)$. These findings support the presence of recent genotoxic exposure. Before GR, we found ABB in 5 of 1900 cells $(0.20 \%)$ : structural abnormalities (SAB, breaks and exchanges) in 5 cells and numerical abnormalities (NAB) in 0 cells. After GR, we found $\mathrm{ABB}$ in 16 of 1900 cells $(0.80 \%)$ : $\mathrm{SAB}$ in 12 and $\mathrm{NAB}$ in 4 cells. The reference value of $\mathrm{ABB}$ for healthy Czech adults is in range of $0-1.88 \%(n=20)(20)$. From the above follows that after using $3 \%$ CCTs-Pix Lithantracis $(0.80 \%)$, the level of aberrated cells was significantly lower than the upper level of reference range $(1.88 \% ; \mathrm{p}<0.01)$. In our previous work, the patients $(\mathrm{n}=20)$ were treated by $5 \%$ CCTs-Pix Lithantracis, and after GR, we found ABB in 56 of 2000 cells (2.80\%) (7). This level was clearly beyond the upper level of reference range $(1.88 \%)$. We suppose that the described difference in findings can be attributed to the different content of PAHs in applied ointments.

GR is used mainly for chronic stable plaque psoriasis with high benefit in patients with refractory psoriasis (28). Also in the presented study, GR therapy PASI score significantly decreased.

\section{Conclusion}

We found elevated levels of circulating biomarkers of cell death (nucleosomes) in patients with plaque psoriasis treated with GR (PAHs, UVR). It is likely that the observed slightly elevated level of $\mathrm{CN}$ is a result of a combination of positive effects 
of therapy (PASI) and its weak genotoxic effect (mainly PAHs). These conclusions are supported by significant correlation between $\mathrm{CN}$ and urinary level of 1-OHP after GR, and elevated level of CA after GR.

\section{References}

1. Gezer U, Mert U, Ozgür E et al. Correlation of histone methyl marks with circulating nucleosomes in blood plasma of cancer patients. Oncol Lett 2012; 3: 1095-1098.

2. Holdenrieder S, Kolligs FT, Braess $\mathbf{J}$ et al. Nature and dynamics of nucleosome release from neoplastic and non-neoplastic cells. Anticancer Res 2012; 32: 2179-2183.

3. Holdenrieder S, Stieber P. Clinical use of circulating nucleosomes. Crit Rev Clin Lab Sci 2009; 46: 1-24.

4. Stoetzer OJ, Wittwer C, Lehner J et al. Circulating nucleosomes and biomarkers of immunogenic cell death as predictive and prognostic markers in cancer patients undergoing cytotoxic therapy. Expert Opin Biol Ther 2012; 12 (Suppl 1): S217-24.

5. Naglova H, Bucova M. HMGB1 and its physiological and pathological roles. Bratisl Lek Listy 2012; 113: 163-171.

6. Henkler F, Stolpmann K, Luch A. Exposure to polycyclic aromatic hydrocarbons: bulky DNA adducts and cellular responses. EXS 2012; 101: 107-131.

7. Borska L, Andrys C, Krejsek J et al. Genotoxic and apoptotic effects of Goeckerman therapy for psoriasis. Int J Dermatol 2010; 49: 289-294.

8. Massari LP, Kastelan M, Gruber F. Epidermal malignant tumors: pathogenesis, influence of UV light and apoptosis. Coll Antropol 2007; 31: $83-85$.

9. Ctirad A, Jan K, Lenka B et al. Serum level of sCD30 molecule but not SCD30L in patients with psoriasis is reduced by Goeckerman's therapy. Int J Dermatol 2011; 50: 1033-1035.

10. Ctirad A, Lenka B, David P et al. Goeckerman's therapy for psoriasis with special reference to serum pentraxin 3 level. Int J Dermatol 2008; 47: 1011-1014.

11. Borska L, Andrys C, Krejsek J et al. Serum levels of the pro-inflammatory cytokine interleukin-12 and the anti-inflammatory cytokine interleukin-10 in patients with psoriasis treated by the Goeckerman regimen. Int J Dermatol 2008; 47: 800-805.

12. Moscaliuc ML, Heller MM, Lee $\mathbf{E}$ et al. Goeckerman therapy: A very effective, yet often forgotten treatment for severe generalized psoriasis. J Dermatolog Treat 2012 [Epub ahead of print].

13. de Miguel R, el-Azhary R. Efficacy, safety, and cost of Goeckerman therapy compared with biologics in the treatment of moderate to severe psoriasis. Int J Dermatol 2009; 48: 653-658.
14. Paghdal KV, Schwartz RA. Topical tar: back to the future. J Am Acad Dermatol 2009; 61: 294-302.

15. Fiala Z, Borska L, Pastorkova A et al. Genotoxic effect of Goeckerman regimen of psoriasis, Arch Dermatol Res 2006; 298: 243-251.

16. Borska L, Andrys $\mathbf{C}$, Krejsek $\mathbf{J}$ et al. Plasma levels of p 53 protein and chromosomal aberrations in patients with psoriasis treated with the Goeckerman regimen. Clin Exp Dermatol 2009; 34: e881-883.

17. Borska L, Smejkalova J, Cerna $\mathbf{M}$ et al. Urinary mutagenicity and genotoxic risk in children with psoriasis after therapeutic exposure to polycyclic aromatic hydrocarbons and ultraviolet radiation. Mutat Res 2010; 696: 144-147.

18. de Rie MA, Goedkoop AY, Bos JD. Overview of psoriasis. Dermatol Ther 2004; 17: 341-349.

19. Gmeier G, Krassnig C, Schmidt $\mathbf{E}$ et al. Fast screening method for the profile analysis of polycyclic aromatic hydrocarbon metabolites in urine using derivatization-solid-phase micro extraction. J Chromatogr B 1998; 705: 132-138.

20. Cerna M, Spevackova V, Batariova A et al. Human biomonitoring system in the Czech Republic. Int J Hyg Environ Health 2007; 210: 495-499.

21. Vousden KH, Lane DP. p53 in health and disease. Nat Rev Mol Cell Biol 2007; 8: 275-283.

22. Massari LP, Kastelan M, Gruber F. Epidermal malignant tumors: pathogenesis, influence of UV light and apoptosis. Coll Antropol.2007; 31: 83-85.

23. Shtilbans V, Wu M, Burstein DE. Evaluation of apoptosis in cytologic specimens. Diagn Cytopathol 2010; 38: 685-697.

24. Kolomecki K, Maciaszczyk P, Stepien H, Stepien T, Kuzdak K, Ulanska J. P53 concentration and soluble FasL (sFasL) serum level as indicators of apoptosis in patients with benign and malignant thyroid tumors. Bratisl Lek Listy 2005; 106: 297-300.

25. Fahmueller YN, Nagel D, Hoffmann RT et al. Predictive and prognostic value of circulating nucleosomes and serum biomarkers in patients with metastasized colorectal cancer undergoing Selective Internal Radiation Therapy. BMC Cancer 2012; 12: 5.

26. Madonna S, Scarponi C, Pallotta $S$ et al. Anti-apoptotic effects of suppressor of cytokine signaling 3 and 1 in psoriasis. Cell Death Dis 2012; 3: e334.

27. Wang Y, Yang H, Li L, Wang H, Xia X, Zhang C. Biomarkers of chromosomal damage in peripheral blood lymphocytes induced by polycyclic aromatic hydrocarbons: a meta-analysis. Int Arch Occup Environ Health 2012; 85: 13-25.

28. Hendriks AG, Keijsers RR, de Jong EM et al. Combinations of classical time-honoured topicals in plaque psoriasis: a systematic review. J Eur Acad Dermatol Venereol 2012. [Epub ahead of print].

Received November 14, 2012. Accepted October 27, 2013. 